\title{
Precarização do trabalho na economia do compartilhamento: a perspectiva de lideranças de associações e de usuários
}

\section{Precarization of work in the sharing economy: the perspective of association leaders and service users}

\author{
Eduardo Paulo Almeida de Sant'Anna ${ }^{1 *}$, Laís Karla da Silva Barreto ${ }^{2}$, Maria Antunizia Gomes ${ }^{3}$
}

\begin{abstract}
RESUMO
A economia do compartilhamento revela-se alternativa aos ambientes de trabalho tradicionais. Propondo ideias de liberdade e flexibilidade, na verdade sua principal característica é a isenção de responsabilidade em relação aos trabalhadores; caracterizando a precarização nas relações de trabalho. Este trabalho analisou aspectos desta realidade sob a perspectiva de lideranças de associações de trabalhadores e de usuários de serviços na cidade de Natal RN. A pesquisa foi realizada em duas etapas. A primeira, por meio de entrevistas com os líderes; e a segunda, um questionário com usuários dos serviços. Os resultados permitem concluir que o processo de precarização vivenciado pelos trabalhadores envolvidos oferece um quadro de insegurança e desproteção social com plena fragilidade laboral.
\end{abstract}

Palavras-Chave: Precarização do trabalho; Uberização; Economia de plataforma; Empresas-aplicativo; Empreendedorismo.

\begin{abstract}
The sharing economy reveals itself as an alternative to traditional work environments. Proposing ideas of freedom and flexibility, in fact its main characteristic is the exemption from responsibility in relation to workers, characterizing the precariousness of labor relations. This work analyzed aspects of this reality from the perspective of leaders of workers associations and service users in the city of Natal, RN. The research was carried out in two stages. The first, through interviews with leaders; and the second, a questionnaire with service users. The results allow us to conclude that the precarious process experienced by the workers involved offers a framework of insecurity and social lack of protection with full labor fragility.
\end{abstract}

Keywords: Precarious work; Uberization; Platform economics; Transportation network companies; Entrepreneurship.

\footnotetext{
${ }^{1}$ Universidade Potiguar. *E-mail: epas727@gmail.com

${ }^{2}$ Universidade Potiguar.

${ }^{3}$ Universidade Potiguar.
} 


\section{INTRODUÇÃO}

Na passagem dos séculos XX e XXI foi marcante o esforço do capitalismo para manter seus níveis de acumulação frente à sua obsolescência natural (DARDOT; LAVAL, 2017). Aproveitando-se do avanço da ciência da tecnologia e da civilização, os níveis de recomposição buscados pelo capital nem sempre são justos com o trabalho. Por vezes, se disfarçam de oportunidades, podem ou não garantir e satisfazer a liberdade prometida, os lucros desejados; e sempre alijam o trabalho de qualquer rede securitária de proteção ou garantia (ANTUNES, 2018; ANTUNES; BRAGA, 2009).

No Brasil, bem como em muitos países que experimentam situações semelhantes, as consequências se revelam com frequência: o desemprego estrutural; dificuldade à livre organização dos trabalhadores; a desregulamentação dos direitos trabalhistas; a terceirização, a regulamentação do trabalho intermitente; a propagação do trabalho informal, do trabalho part-time, do trabalho em domicílio; fenômeno que alguns teóricos cunharam de "uberização" do trabalho (SLEE, 2017; ALVES, 2013; BRAGA, 2012).

Este contexto envolve várias transformações por que passam o mercado de trabalho, concomitante com ao crescimento da utilização de smartfones, redes sociais e aplicativos (APP's); mudanças que influenciam os hábitos de consumo e postura da sociedade. Experimentamos uma nova realidade, a Economia Compartilhada. Aqui trabalhadores tornam-se perfis virtuais com atividade material e tangível, fonte de informação para controle, organização e distribuição de seu tempo e espaço, mas agora programado e executado por um aplicativo e seus inúmeros algoritmos (BOTSMAN; ROGERS, 2011).

É em verdade uma nova classe, o precariado (STANDING 2017a, 2017b). "Estas pessoas do precariado estão sendo induzidas a aceitar uma vida de empregos instáveis, sem uma identidade ocupacional, tendo que fazer muitos serviços que, na verdade, não são trabalho... ...neles, os trabalhadores estão sendo explorados fora de um emprego, fora de um espaço físico e horários regulares de trabalho. Eles não têm férias remuneradas, ou a perspectiva de aposentadoria. E por serem os salários baixos e voláteis, ou até mesmo imprevisíveis, eles normalmente estão com dívidas e com medo de perder suas rendas subitamente. Por último, o precariado está no processo de perda de todas as formas de direitos, sejam eles civis, culturais, sociais, econômicos e políticos. A perda de direitos políticos vem do simples fato de que o precariado não vê partidos ou líderes políticos os representando". Continua Standing (2017b), "a flexibilidade é uma daquelas palavras 
usadas demais e ideologicamente orientadas; a maioria de nós quer ser flexível e adaptável, mas não queremos estar inseguros".

Diante disso, a questão de pesquisa do estudo reside em investigar percepção dos processos de precarização do trabalho a partir da visão de lideranças de associações representativas e usuários dos serviços de transportes via aplicativo na cidade de NatalRN.

\section{REFERENCIAL}

O Mundo do trabalho experimenta atualmente um momento de transição. A quarta revolução industrial e seus atributos da inteligência artificial, grandes acervos de dados (Big Data), a internet das coisas ${ }^{4}$, computação em nuvem, sistemas ciber-físicos, exercem franca comunicação e cooperação entre si e com as pessoas em tempo real. De forma paralela e umbilicalmente ligada surge uma nova economia, denominada de "Economia 4.0" ou economia digital, ou ainda economia compartilhada. Apresentada sob a forma de consumo colaborativo, oferece de forma simples e rápida acesso a bens e serviços, através de conexão denominada peer to peer (P2P), em que o comercializador de bens ou prestador de serviços está diretamente ligado ao consumidor final através de uma plataforma ou site ligada à rede mundial de computadores, possibilitando interação direta entre oferta e demanda, eliminando intermediários e possibilitando a configuração diferente da economia tradicional. (BOTSMAN; ROGERS, 2011).

Neste novo modelo econômico, as relações de trabalho se apresentam de forma igualmente diferente. Ao interligar diretamente ao consumidor final, a prestação do serviço através de um aplicativo (APP), as plataformas sugestionam realizar conexão de atividade autônoma ao consumidor final, como a desenvolver negócios a verdadeiros microempreendedores, encerrando, pois, uma relação - percebida ou não - de trabalho.

\subsection{A Economia digital e o trabalho}

${ }^{4}$ Termo criado em 1999 por Kevin Ashton do MIT para a ideia de unir de forma permanente a maior parte possível das coisas do mundo físico e o mundo digital, tornando-os um só, através de dispositivos que mantenham comunicação entre si e data centers e suas "nuvens". 
A economia do compartilhamento revela em uma sociedade orientada por informações, nas quais a lista do que pode ser transformado em dados é comoditizado batimentos cardíacos, conversas, nossas preferências expressas com base no aumento da quantidade de dados que partilhamos, consciente ou inconscientemente, produzindo uma pegada digital que pode ser analisada em nosso favor, ou não (WEST, 2017). A literatura, tentando entender como essa economia funciona, cunhou termos distintos para tal fenômeno; "capitalismo de dados"5" (WEST, 2017), "economia de vigilância ${ }^{6 "}$ (ZUBOFF, 2015), "capitalismo de plataforma" (SRNICEK, 2017) e complexo industrial da informação ${ }^{7}$ "(POWERS; JABLONSKI, 2015), entre outros nomes.

Uma das principais preocupações levantadas sobre a economia digital foram o impacto potencialmente prejudicial que o 'trabalho de bico ${ }^{81}$ (às vezes chamado de trabalho de varejo, trabalho em plataforma ou trabalho a um clique), tem a posição de barganha de trabalhadores coletivos e individuais (MOORE, 2018).

Apesar dessas preocupações, também vemos um "discurso oficial" que propõe a autonomia a ser ofertada ao abraçar a oportunidade que o trabalho de "conveniência" tem para oferecer. Trata-se em verdade de uma promessa semelhante a uma espécie de "liberdade fictícia" (KLEIN, 2017), segundo o qual cresce permanentemente o nível de controle e pressão exercidos sobre os trabalhadores é igualmente retratado como uma modalidade de concessão de autonomia de trabalho por conta própria, de liberdade, de definitivamente ser livre para empreender ou de se estabelecer autonomamente.

${ }^{5}$ Capitalismo de dados termo criado por Sarah Myers West, para teorizar que uma era que os dados estão "comoditizados", a sua posse deixará o poder assimétrico e com quem os detiver.

${ }^{6}$ Economia de vigilância, termo utilizado e popularizado pela acadêmica Shoshana Zuboff, para transformação em valores monetários de todos os dados adquiridos por vigilância.

${ }^{7}$ Complexo Industrial da Informação, conceito que assegura a sustentabilidade entre o tripé Governo, tecnologia e economia, exemplificado pelos autores Shawn Powers e Michael Jablonski em sua obra The Real Cyber War, 2015) e a simbiose derivada da mútua dependência destes atores (Governo, Economia, Vale do Silício) que resultou na teoria de complexo industrial de informação.

8 Trabalho sob demanda, ou trabalho "de bico". Nos trabalhos de língua inglesa utilizase a expressão: "show" 
A inovação tecnológica, característica da economia compartilhada, trouxe consigo mudanças significativas na organização do trabalho, nas relações de emprego e trabalho, com impactos te toda natureza. A aumento do uso da tecnologia, caraterística da economia compartilhada, contribuiu significativamente para rápido crescimento do trabalho de “demanda", fazendo proliferar na razão direta das plataformas de trabalho. É um novo mercado de trabalho que floresce cada vez mais a taxas exponenciais. A tecnologia, unindo plataformas à mão de obra, sem intermediários (peer-to-peer). Plataformas de trabalho usam tecnologia conectando trabalhadores com consumidores para tarefas pontuais ou trabalhos virtuais ou ainda pessoas para uma força de trabalho sob demanda. Essa força de trabalho pode operar com recursos sociais e trabalhistas limitados sem proteções, que se tornam cada vez mais relevantes à medida que mais trabalhadores confiam nas plataformas como principal fonte de renda.

A nova economia alega que o trabalho pode proporcionar aos trabalhadores a oportunidade de alcançar um grau aprimorado de autonomia em termos de escolha de quais tarefas executar, em que trabalhar e quando trabalhar. De fato, é esse apelo à "autonomia" que talvez seja central para esse discurso oficial que anuncia e identifica vantagens das novas formas de trabalho 'desregulamentados' que são aspectos centrais da nova economia digital. Isso inclui: um apelo à maior inclusão e acessibilidade que o trabalho tradicional oferece, em particular ao disponibilizar oportunidades a um maior número de pessoas, incluindo aquelas cuja mobilidade ou a disponibilidade impede que eles trabalhem horas regulares (VALENDUC; VENDRAMIN, 2016, p. 32); a afirmam que o trabalho de "bico" é capaz de resolver desafios geográficos para os trabalhadores, permitindo identificação mais próxima entre oferta e demanda de habilidades (KITTUR et al. 2013, p. 24); e a possibilidade de que o trabalho de "bico" possa "democratizar" a geração de ideias "(BERGVALL-KAREBORN; HOWCROFT, 2014, p. 215).

A noção, presente no "discurso oficial", de que o trabalho de demanda representa uma nova forma de emprego autônomo, no qual os trabalhadores são liberados para buscar uma seleção muito maior oportunidades de emprego, é, portanto, questionável. É nesse sentido que poderíamos mais conceituar adequadamente o discurso oficial do trabalho sob demanda como sendo construído sobre uma noção de liberdade "(KLEIN, 2017). Ou seja, o discurso do trabalho pró-demanda baseia-se, de uma maneira unilateral, em oportunidades para maior autonomia que o trabalho de demanda pode proporcionar, 
ocultando ou negligenciando as restrições substanciais que existem e que agem para impedir o exercício dessa suposta autonomia.

Para Klein (2017), essa noção de liberdade, ou 'autonomia', é 'fictícia'. Ele apresenta mercado como um mecanismo neutro através do qual os atores econômicos podem adquirir maior liberdade como resultado das oportunidades de entrar em atos de troca que o mercado oferta. No entanto, a imposição do próprio mercado reflete lutas políticas subjacentes que não podem ser considerados neutro ou fora do escopo das relações de poder (desiguais). Promoção do mercado como meio através do qual se promete garantir maior liberdade, reflete, portanto, as relações de poder subjacentes que são marcados por desequilíbrios e relações de dominação e subordinação.

\section{METODOLOGIA}

Em nosso estudo definimos duas etapas de investigação, uma abordagem quantitativa e uma qualitativa devido a sua subjetividade acerca da coleta, análise e interpretação dos dados. A cidade de Natal -RN foi a área definida para nossa pesquisa.

A primeira etapa realizamos entrevistas com dirigentes de associação representativa de motoristas de aplicativos de mobilidade urbana da cidade de Natal-RN. Por meio de entrevistas semiestruturadas, com aspectos investigados baseados na literatura. As entrevistas com lideranças foram priorizadas em virtude de a classe de profissionais contar coma forte individualização do trabalho, esfacelamento do coletivo e dificuldade de organização, relatados inclusive por Druck (2020), além da oportunidade de registrar na literatura o sentido das respostas das lideranças através da análise de conteúdo.

Nosso estudo teve como objetivo investigar a percepção dos dirigentes representativos da categoria sobre os processos de precarização do trabalho entre os motoristas por aplicativo. Assim, com base na literatura utilizada no referencial, elaboramos roteiro com vinte perguntas, que entendemos satisfazer os objetivos da pesquisa.

A coleta de dados foi iniciada com levantamento bibliográfico a respeito dos temas abordados na entrevista que são parte integrante da contextualização, planejamento e referencial do presente estudo, e que orientaram e embasaram a estruturação dos questionários utilizados (BARRIBAL; WHILE, 1994; MORSE, 2006, CRESWELL, 2014). 
Assim, com base na literatura utilizada no referencial, elaboramos roteiro com vinte perguntas, que entendemos satisfazer os objetivos específicos da pesquisa e aguardou o pré-teste com objetivo de esclarecer questões e obter novos dados, além de possíveis inconsistências, bem como a retificação de itens necessários.

Na segunda etapa aplicamos um questionário com usuários do sistema de transporte por aplicativos da cidade de Natal-RN. O questionário foi construído a partir de a partir de critérios de conveniência e acessibilidade para a coletas de dados.

Nosso objetivo foi conhecer a percepção dos pesquisados, usuários do sistema, sobre os processos de precarização do trabalho entre os motoristas por aplicativos.

O questionário aplicado no campo foi idealizado com base no referencial utilizado no presente estudo. As opções de respostas - em número de cinco - variaram entre discordo totalmente, discordo parcialmente, nem discordo nem concordo, concordo parcialmente e concordo totalmente, para as assertivas apresentadas.

Intitulado, Utilização de Transporte por aplicativos em tempos de pandemia COVID-19 (Uber, 99, etc.), o questionário foi realizado através do sistema GOOGLE FORMS, com geração de link distribuído aleatoriamente em grupos de rede social "Whatsapp" e a partir daí no sistema de "bola de neve". Realizamos pré-teste com 11 respondentes não observando necessidade de ajustes. Os respondentes do pré-teste foram incluídos no resultado. Não observamos a ocorrência de outliers. Ao final, tivemos o total de 215 respondentes.

\section{RESULTADOS}

4.1 As entrevistas com lideranças de associações

Em nossa análise de dados da entrevista, privilegiamos o uso da codificação simples para, a partir daí, combinar em quantidades menores de informação que oportunizasse sentido na busca de nosso objetivo de pesquisa.

Assim, obtivemos núcleo de sentido que revela o contexto dos pesquisados em relação à nossa questão de pesquisa: Qual a percepção dos processos de uberização do trabalho a partir da visão de dirigentes de classe e usuários dos serviços de transportes via aplicativo na cidade de Natal-RN?

As entrevistas realizadas evidenciam que os dirigentes entendem que as pessoas buscam acesso a trabalho como motoristas por aplicativos em decorrência de dificuldades enfrentadas na busca por emprego. 
Os gestores de entidade de motoristas por aplicativos entendem que fazem e participam de um negócio. Se percebem como autônomos e, portanto, como empreendedores que têm um negócio próprio e gerido individualmente; se organizam, planejam e criam estratégia individualmente. A forma de organização do trabalho demonstra um mínimo de orientação por parte das entidades representativas na orientação de planejamento das atividades. Conforme Josué, Dirigente Classe (2020) "o motorista tem muita liberdade aqui em Natal, cada um faz seu modelo e trabalha de acordo com sua conveniência e interesse".

Os gestores dirigentes de classe na cidade de Natal revelam satisfação com o modelo, entretanto vivem momento de muita expectativa e angústia em virtude de pressões diretas ou indiretas das plataformas. Assim, os dirigentes relatam momento de forte pressão com o cadastramento em massa que as plataformas estão realizando ao longo dos últimos meses de novos motoristas sem, entretanto, torná-los ativos, fato que gera um excepcional excedente estimado atualmente pelos dirigentes em três vezes o número atual da frota ativa.

As pressões exercidas pelas plataformas são observadas na literatura, por exemplo em Kittur et al., (2013) para quem a prática gera trabalhadores flexíveis, baratos e sob demanda, comprometendo direitos e contribuindo para criação de profissionais cada vez mais precarizados e Rosenblat (2016) quando registra que as plataformas implementam regimes extensos de vigilância, rastreamento e coordenação, que perpassa a neutralidade da mediação; moldam e alteram a experiência do trabalho.

As pressões exercidas pelas plataformas funcionam bem. A recente ação de cadastro em massa foi um sucesso no caso da UBER na praça de Natal. Em conjunto com locadoras, financeiras, seguradoras, que se encarregaram de divulgar a marca e criaram produtos exclusivos para motoristas por aplicativos, além de frotistas - um novo segmento muito bem-vindo ao mercado- atraíram um verdadeiro exército para o segmento. Em ação articulada preços caíram, prazos aumentaram; novas e melhores condições foram implementadas para uma praça que se revela interessante, são novas condições, novos tempos, diferentes tempos.

São excelentes mecanismos de desmonte de qualquer tentativa de união entre os motoristas, potencial que o trabalho de demanda tem de erodir o coletivo, aumentando a pressão sobre os trabalhadores para competir no mercado de trabalho, resultando em redução do padrão de vida. A classe entendia que tinha experimentado avanços na solução 
ou discussão de temas como: possibilidade não aceitação serviço, suspensão penalização após três recusas, notas avaliação mínimas, penalidades suspensão, desligamento etc., evidências indicam que as empresas estão mudando os relacionamentos existentes com os parceiros nas plataformas de trabalho. De acordo com João, Dirigente Classe (2020) "é uma pressão fortíssima, todos sentem muito!"

É mais um fator de divisão da categoria que já apresenta sérias dificuldades em reunir. São momentos de franco esfacelamento das posições coletivas e de posições antagônicas que apenas à plataforma interessam e justificam. Para a entidade de classe, é a face negra, mais perversa que se mostra; deixando à mostra a desagregação dos motoristas quando deveriam mais unir. A pressão constante estabelecida sobre os trabalhadores para competir no mercado de trabalho leva a erosão do coletivo, mina os salários e condições de trabalho, resultando em redução dos padrões de vida das pessoas.

Os gestores dirigentes de classe não reconhecem explicitamente que há excesso de vigilância das plataformas no relacionamento. Entretanto, ao registrar que o compartilhamento das informações colhidas pela plataforma dos motoristas é negado, revelam a existência da prática. "[...]o que eu vejo é a falta de compartilhamento dos dados, isso não é bom; os dados têm que ser abertos com cada motorista (João, dirigente de classe, 2020)".

Os gestores entrevistados relatam que os processos de gerenciamento das plataformas são opacos. Dada a falta de transparência sobre como os algoritmos funcionam, os trabalhadores sob demanda enfrentam significativos esforços de criação de sentido para se familiarizar com processos de controle sob os quais seu trabalho está estruturado.

É o que ocorre, por exemplo, na monitoração da aceleração de motoristas, da verificação de hábitos de interrupção dos dispositivos celulares, do rastreamento dos motoristas por horas de trabalho, enfim um grande trabalho de vigilância parte da infraestrutura algorítmica de monitoramento.

As plataformas ativaram uma grande quantidade de motoristas na praça que atingiu um nível de saturação. A maioria dos motoristas são influenciados por faturamento cada vez maior", ou é o trabalho eventual, "não real" realizado somente no tempo destinado ao lazer, logo o reflexo é direto no nível de descanso levando a jornadas exaustivas dificultando o motorista de se desconectar. 
A formalização de vínculo trabalhista com empresas plataformas de aplicativos não é uma opção considerada pelos motoristas. Várias justificativas são citadas, como por exemplo: a impossibilidade de trabalhar para várias plataformas elegendo eventualmente as melhores opções momentâneas, necessidade de cumprimento de jornada de trabalho, remuneração fixa dentre outros.

Os gestores dirigentes de classe entendem que os profissionais que trabalham por aplicativos experimentam na segurança seu mais evidente problema atual. Além dos problemas advindos do relacionamento com a plataforma, exercida através do cadastramento em massa de novos motoristas sem ativação formando um "exército de reserva" pronto para atuar a qualquer momento, a forte vigilância e o controle do trabalho, com consequente penalização; tem na segurança pública um fator crítico.

As entrevistas evidenciam ainda que os profissionais se percebem como autônomos, revelam satisfação com o modelo, entretanto vivem momento de muita expectativa e angústia em virtude de pressões diretas ou indiretas das plataformas.

Finalmente, as entrevistas sugerem um quadro de fragilidade laboral com desproteção social que tem início no quadro de dificuldade estrutural de emprego na economia tradicional, que oportuniza o ingresso destas pessoas na economia compartilhada. A ilusão inicial da liberdade e do empreendedorismo dá lugar à realidade da super individualização de um trabalho fracionado, com o completo esfacelamento coletivo gerado pela ampla competição e consequente desunião, pressão permanente, controle, vigilância, ameaças de penalização que geram insegurança, trazendo ao quadro inicial de desilusão quando o ciclo pernicioso novamente inicia.

\subsection{Os questionários com usuários dos serviços de transporte por aplicativo}

Os resultados obtidos com o questionário aplicado aos usuários do sistema de mobilidade urbana por aplicativo na cidade de Natal revelaram os dados adiante.

Nosso primeiro questionamento foi sobre a jornada de trabalho dos motoristas por aplicativo. Quando questionados, os usuários dos serviços, se entendem que os motoristas de transporte por aplicativo têm uma jornada de trabalho justa, obtivemos as respostas como no gráfico 1 adiante.

A maioria do total de respondentes (215/121), que corresponde ao percentual de $56,3 \%$, entendem que a jornada de trabalho dos motoristas por aplicativos não é justa. Este achado encontra amparo em Antunes e Filgueiras (2020), para quem as longas 
jornadas refletem a luta pela sobrevivência, como resultado da instabilidade nas tarifas e nas baixas remunerações. Isso gera trabalhadores flexíveis, baratos e sob demanda, comprometendo direitos e contribuindo criação trabalhadores cada vez mais precarizados" (KITTUR et al., 2013).

Gráfico 1 - Os motoristas por aplicativos têm uma jornada de trabalho justa

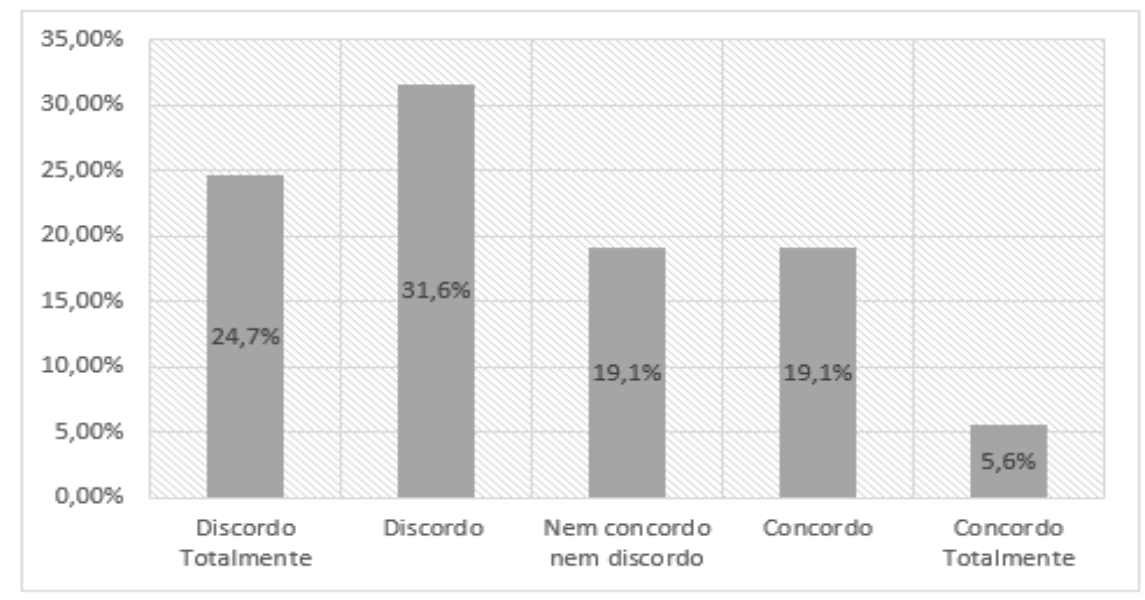

Fonte: Elaborado pelo autor (2021).

Em seguida, questionamos sobre o monitoramento dos motoristas por parte da empresa de aplicativos e se os motoristas tinham suas decisões limitadas.

Gráfico 2 - Os motoristas por aplicativos são monitorados pelo aplicativo: suas decisões são limitadas (não podem fazer um roteiro alternativo, uma parada não programada etc.)

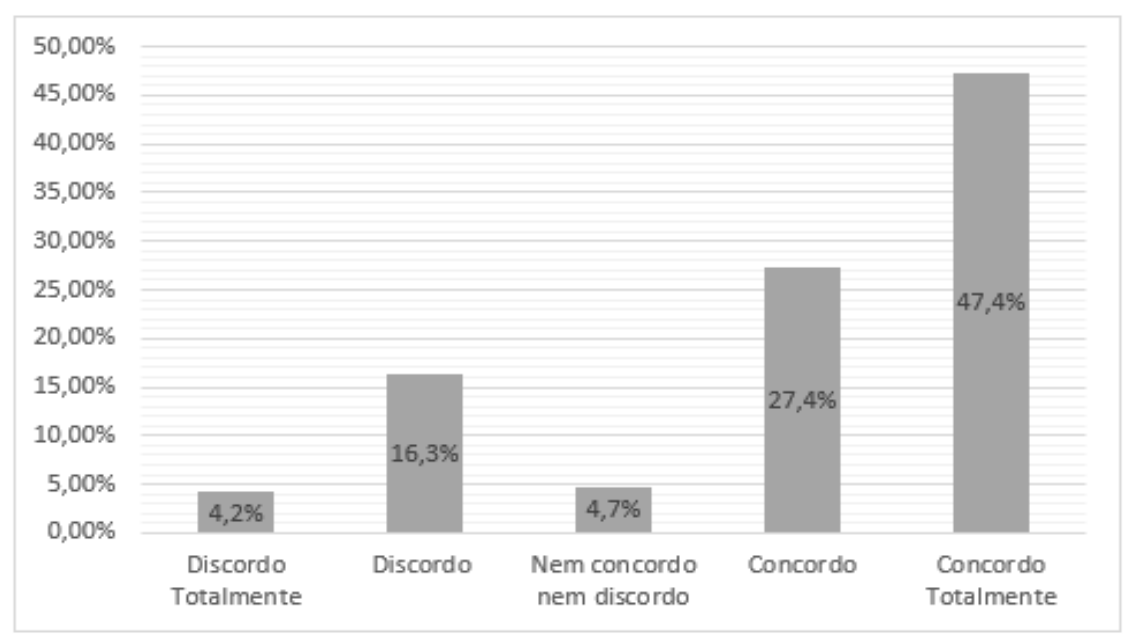

Fonte: Elaborado pelo autor (2021)

Os usuários do sistema entendem e reconhecem de forma majoritária a existência de monitoramento sobre os profissionais motoristas por aplicativos. Os resultados das 
opções de concordância e concordância total somam 161 de 215 (74,8\%) respondentes. Estes números revelam que a prática limita a atuação do profissional, achado condizente com o encontrado e relatado por Rosenblat (2016), que o controle perpassa a neutralidade da mediação; Griswold (2018) e Ticona, Mateescu e Rosenblat (2018), que o controle sobre o trabalho varia entre plataformas e abala a relação com parceiro; e diferente do admitido e justificado pela própria Uber (2019) de que apenas controla aceleração e horas trabalhadas dos motoristas.

Quando perguntamos se o sistema de avaliações utilizados pelas empresas de aplicativos com os motoristas é justo, percebemos que os usuários concordam (149 do total de 215 respondentes) com o sistema de avaliações, conjunto de dados filtrados classificados e coordenados pela plataforma, relatado por Lustig et al. (2016) que estabelecem uma média de classificação dos passageiros aos motoristas (GRISWOLD, 2018). Entendem que é justo de forma amplamente majoritária $(69,3 \%)$. Trata-se da oportunidade de avaliar o serviço recebido, sabendo antecipadamente que de igual forma receberá também uma avaliação (gráfico 3).

Gráfico 3 - O sistema de avaliações usados pelos aplicativos com os motoristas é justo

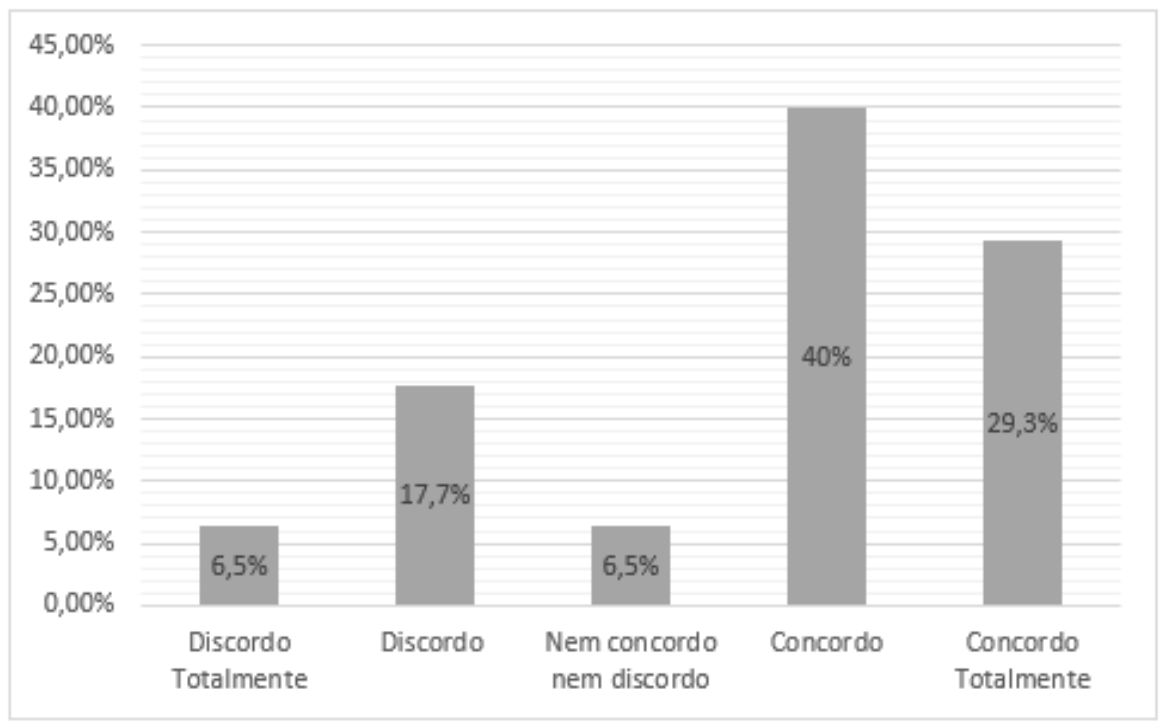

Fonte: Elaborado pelo autor (2021)

O gráfico (04) a seguir representa o resultado do questionamento a respeito da penalização das empresas com os motoristas e se são justas. 
Gráfico 4 - As penalidades impostas pelos aplicativos para motoristas que tem avaliações consideradas abaixo do padrão são justas

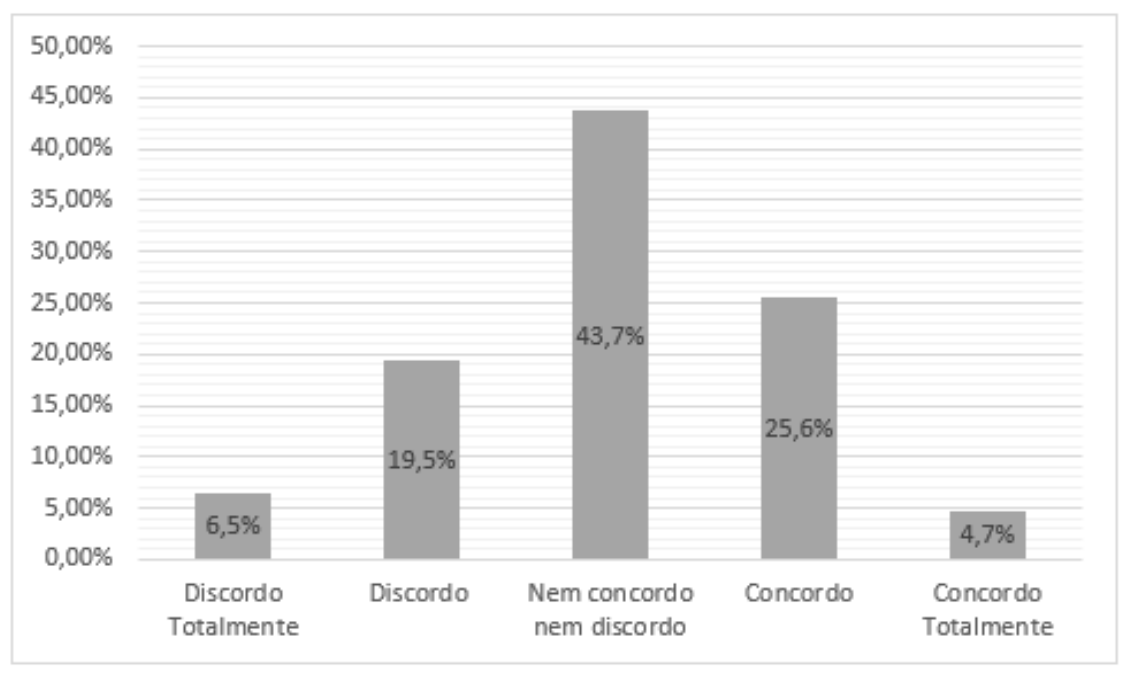

Fonte: Elaborado pelo autor (2021).

Neste quesito, os achados demonstram que, há uma divergência na percepção dos motoristas em relação as penalidades impostas pelos aplicativos, assim não sendo possível aferir com segurança uma resposta contundente. Em seguida a temática foi sobre as taxas cobradas dos motoristas por parte das empresas aplicativos. As respostas estão representadas no gráfico 5 adiante.

Gráfico 5 - As taxas que os aplicativos cobram dos motoristas são justas

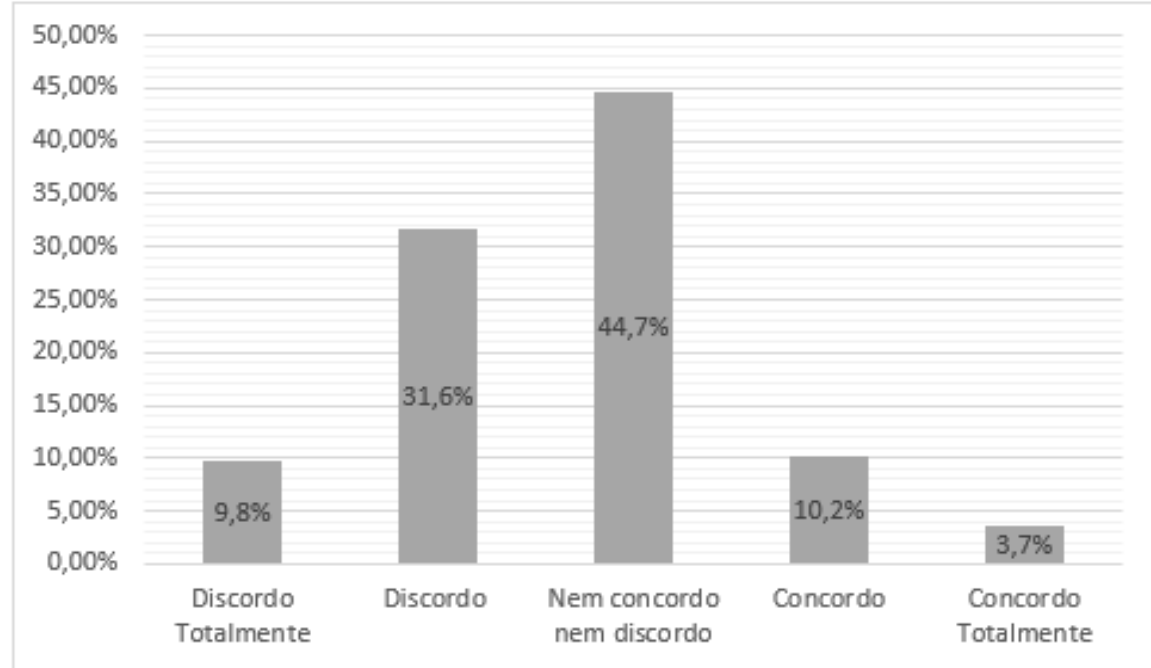

Fonte: Elaborado pelo autor (2021). 
Os usuários do sistema de transporte por aplicativo manifestam discordância sobre as taxas cobradas aos motoristas por aplicativos por parte das empresas, apesar de não formar maioria de opiniões (41,4\% discordam; 13,9\% concordam). O sentimento expressado revela mais uma face da uberização do trabalho citado em Moore (2018), de que a economia digital tem posição de barganha entre trabalhadores coletivos e individuais, e converte-se em importante mecanismo para a imposição de longas jornadas (ANTUNES, FILGUEIRAS, 2020), contribuindo para criação de trabalhadores cada vez mais precarizados (KITTUR et al., 2013).

O gráfico 6 abaixo representa o resultado de uma pergunta direta realizada como nossa sexta questão de pesquisa com usuários do sistema de transporte por aplicativo, que foi qual a opinião do usuário dos serviços de transporte por aplicativo, se o motorista é um autônomo empreendedor ou é um empregado da empresa?

Gráfico 6 - Em sua opinião, o motorista por aplicativo é um autônomo empreendedor OU é um empregado da empresa de aplicativos?

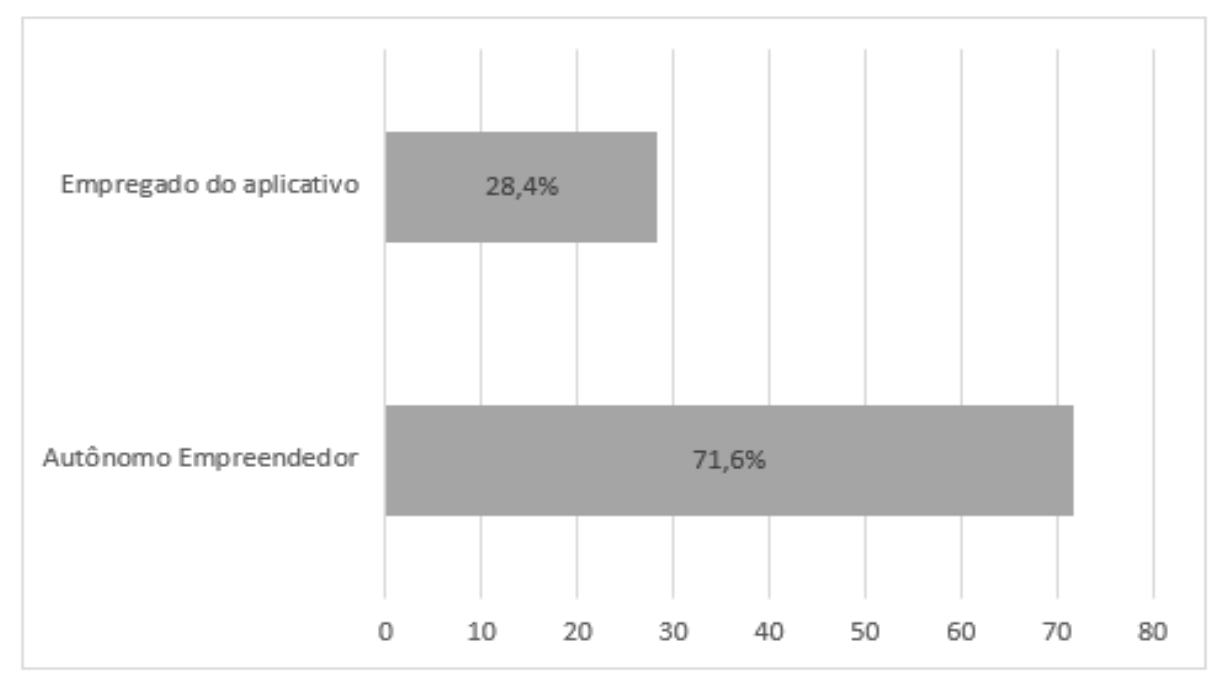

Fonte: Elaborado pelo autor (2021)

Para ampla maioria dos usuários, os motoristas por aplicativos se constituem em autônomos empreendedores. Nossa pesquisa com usuários do serviços de transporte por aplicativo respalda e confirma as entrevistas realizadas na primeira etapa com os dirigentes de classe, que mantém igual posicionamento. 
Os resultados encontrados são coerentes com Davidov, Freedland e Kountouris (2017) para quem a nova economia, com novas formas e meios de produção proporciona liberdade e tempo de dispor livremente sua força de trabalho, sem amarras de contratos típicos de trabalho e características de autônomo empreendedor.

Entretanto, em Antunes e Filgueiras (2020), apenas é revelado o controle que mantém o trabalhador em completa instabilidade, aproveitando-se de sua vulnerabilidade, permitindo uma subordinação cada vez mais exacerbada pela transferência de riscos que visa tão somente legitimar uma nova estratégia do capital.

Nosso próximo questionamento de pesquisa foi sobre a percepção dos usuários a respeito dos motoristas por aplicativos, e está representada no gráfico 7. Apresentamos a frase: Os motoristas por aplicativos sempre parecem... Em seguida oferecemos sete opções que os respondentes poderiam marcar várias opções. Os resultados, portanto, refletem as opções mais assinaladas pelo conjunto de respondentes (215).

Gráfico 7 - Os motoristas por aplicativos sempre parecem[...]

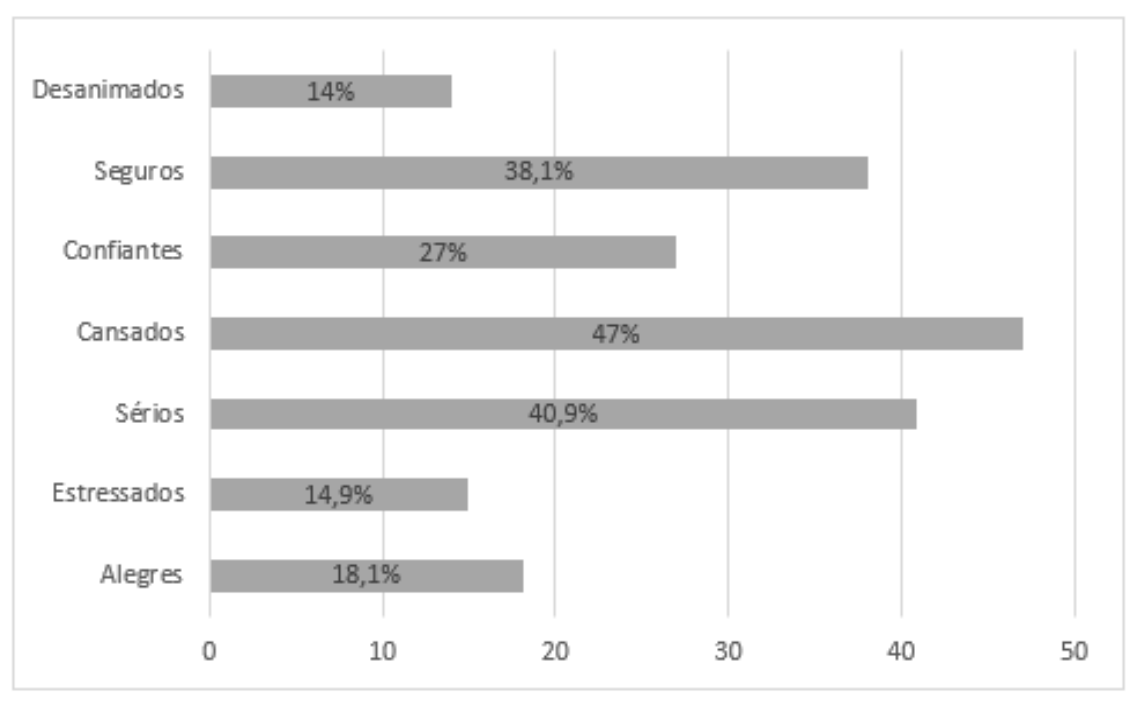

Fonte: Elaborado pelo autor (2021).

Assim, aos usuários do sistema de transporte por aplicativo, os motoristas sempre parecem: cansados (47\% dos respondentes), sérios (40,9\% dos respondentes) e seguros $(38,1 \%$ dos respondentes $)$.

A análise das respostas evidencia que os usuários do sistema de mobilidade urbana por aplicativo percebem que os motoristas não têm jornada justa de trabalho, são 
monitorados pela empresa aplicativo, entendem que as taxas cobradas por partes das empresas são injustas e os motoristas sempre parecem estar cansados.

Para ampla maioria dos usuários, os motoristas por aplicativos se constituem em autônomos empreendedores. Nossa pesquisa com usuários do serviços de transporte por aplicativo respalda e confirma as entrevistas realizadas na primeira etapa com os dirigentes de classe, que mantém igual posicionamento.

Os resultados encontrados são coerentes com Davidov, Freedland e Kountouris (2017) para quem a nova economia, com novas formas e meios de produção proporciona liberdade e tempo de dispor livremente sua força de trabalho, sem amarras de contratos típicos de trabalho e características de autônomo empreendedor.

Entretanto, em Antunes e Filgueiras (2020), apenas é revelado o controle que mantém o trabalhador em completa instabilidade, aproveitando-se de sua vulnerabilidade, permitindo uma subordinação cada vez mais exacerbada pela transferência de riscos que visa tão somente legitimar uma nova estratégia do capital.

\section{CONCLUSÕES}

Este artigo permite considerar que as relações entre os trabalhadores da economia digital e as plataformas, com foco em análise com lideranças de associações representativas de trabalhadores com aplicativos de transportes, é marcada por relações desiguais, desproteção social, impactos psicossociais resultados de pressões, forte vigilância, falta de transparência, em um processo franco e crescente de precarização do trabalho. Paralelamente às dificuldades enfrentadas na esfera laboral, os trabalhadores têm hoje na segurança pública seu maior e mais desafiador problema.

De igual forma, nossos achados com os usuários dos serviços de transporte por aplicativo, corroboram a percepção de relações desiguais entre os motoristas e empresas de aplicativos. Os usuários entendem que a jornada de trabalho dos motoristas não é justa, que suas ações são monitoradas pelas empresas e discordam das taxas cobradas dos motoristas.

Estas percepções emergem do núcleo de sentido de nosso questionário e reforçam os achados da entrevista realizada com dirigentes. Aos usuários, apesar de perceberem os motoristas por aplicativos como autônomos empreendedores, estes sempre perecem estar "cansados", "sérios". 
Diante deste quadro, resta-lhes, pois, o crônico problema estrutural de emprego da economia tradicional ou as "oportunidades" da nova economia e suas formas diretas ou indiretas de precarização e vilipêndio das condições de trabalho e do trabalhador.

A relevância do tema para o ambiente acadêmico é evidenciada por tratar de tema contemporâneo, de apelo social e de presença significativa em nossa cidade, região, Estado. Este estudo tem escopo e potencial indutor de novas pesquisas e referência para novos estudos, como importante ponto de partida.

De igual forma, revela-se importante para sociedade por conter temática sensível, atual e sempre presente nas casas legislativas.

Às entidades governamentais em suas três esferas de atuação revela-se instrumento de alerta, identificação e sugestão de ações que podem auxiliar trabalhadores com programas de capacitação administrativo/gerencial, atendimento, interlocução, fluência em idiomas, condução, mobilidade, sustentabilidade etc.; prevenção e coibição de precarização do trabalho e suas várias facetas e finalmente a intermediação entre as plataformas e trabalhadores.

A disseminação de trabalhos de baixa qualidade com poucos benefícios é fonte de insegurança que deve ser abordada. Para fazer uma transição bem-sucedida para as economias digitais, os governos devem facilitar a troca de emprego e garantir aos trabalhadores uma parcela justa dos benefícios dessa transição. As soluções potenciais devem incluir a garantia de condições paritárias nas negociações inclusive salariais, participação nos lucros e cooperativas.

Superar os desafios da nova economia significa repensar os direitos e obrigações da cidadania; limites os quais concordam os indivíduos na troca de suas inalienáveis liberdades para satisfação dos interesses da sociedade.

Importante reconhecer as limitações das pesquisas constantes do presente estudo. Inicialmente, por contemplar apenas uma das entidades representativas dos profissionais motoristas por aplicativos e em seguida por delimitar a cidade de Natal, que, de fato, representa na prática os profissionais do Estado do Rio Grande do Norte.

Por fim, registre-se a sugestão de replicação da metodologia apresentada na pesquisa, com aprimoramentos necessários considerando-se a provável situação de póscrise, ou como instrumento auxiliar em outras pesquisas no universo ora analisado, assim como estudos comparados com motoristas de cooperativas de trabalho. 


\section{REFERÊNCIAS}

ALVES, G. O que é precariado? São Paulo: Boitempo, 2013. Disponível em: https://blogdaboitempo.com.br/2013/07/22/o-que-e-o-precariado/. Acesso em: 5 abr. 2020.

ANTUNES, R. O privilégio da servidão: o novo proletariado de serviços na era digital. São Paulo: Boitempo, 2018.

ANTUNES, R.; BRAGA, R. (orgs.). Infoproletários: degradação real do trabalho virtual. São Paulo: Boitempo, 2009.

ANTUNES, R.; FILGUEIRAS, V. Plataformas Digitais, Uberização do trabalho e regulação no capitalismo contemporâneo. Contracampo, Niterói, v. 39, n. 1, p. 27-43, abr./jul. 2020.

BARRIBALL, K. L.; WHILE, A. Collecting data using a semi-structured interview: a discussion paper. Journal of Advanced Nursing, v. 19, p. 328-335, 1994

BERGVALL-KAREBORN, B.; HOWCROFT, D. Amazon Mechanical Turk and the commodification of labour. New Technology, work and employment, n. 29, p. 213223, 2014. DOI: doi.org/10.1111/ntwe.12038.

BOTSMAN, Rachel; ROGERS, Roo. O que é meu é seu: como o consumo colaborativo vai mudar o nosso mundo. Porto Alegre: Bookman, 2011.

BRAGA, R. A política do precariado: do populismo à hegemonia lulista. São Paulo: Boitempo, 2012.

CHESNAIS, François. A mundialização do capital. São Paulo: Xamã, 1996.

CRESWELL, J. W. Investigação qualitativa e projeto de pesquisa: escolhendo entre cinco abordagens. Porto Alegre: Penso, 2014.

DARDOT, P.; LAVAL, C. A nova razão do mundo: ensaio sobre a sociedade neoliberal. São Paulo: Boitempo. 2017.

DAVIDOV, G.; FREEDLAND, M.; KOUNTOURIS, N. The Subjects of Labour Law: Employees and other Workers in Finkin, M., and Mundlak, G. Cheltenham, UK: Comparative Labor Law, 2017.

DEGRYSE, C. Digitisation of the economy and its impact on labour markets. Working Paper, 2016.

GRISWOLD, A. Uber Limits Driver Hours in the US to Reduce Crashes from Drowsy Driving. Quartz, 2018. Disponível em: https://qz.com/1204615/uber-is-getting-seriousabout-keeping-drowsy-drivers-off-the-road/. Acesso em: 8 jan. 2021.

KITTUR, A. et al., The future of gig work. [S.l.]: CSCW. 2013. 
KLEIN, S. Fictitious freedom: a Polanyian critique of the republican revival. American journal of political science, 2017. DOI:10.1111/ajps.12317.2017.

LUSTIG, C. et al. Algorithmic Authority: The Ethics, Politics, and Economics of Algorithms That Interpret, Decide, and Manage. In: CHI EA '16. Proceedings of the CHI Conference on Human Factors in Computing Systems (Extended Abstracts), San Jose, CA, maio 7-12, New York, NY: ACM.2016. p. 1057-1062.

MOORE, P. The quantified self in precarity: work, technology, and what counts. London: Routledge, 2018.

MORSE, J. M. Biased reflections: Principles of sampling and analysis in qualitative inquiry. In: POPAY, J. (ed.). Moving beyond effectiveness in evidence synthesis: methodological issues in the synthesis of diverse sources of evidence. London: National Institute for Health and Clinical Excellence, 2006.

POWERS, S.; JABLONSKI, M. The real cyber war: the political economy of internet freedom. Chicago, IL: University of Illinois Press, 2015.

PRIBERAM, Dicionário Priberam da Língua Portuguesa, 2006.

https://dicionario.priberam.org. ISBN 9729919127 <consultado em 13.10.2020>

ROSENBLAT, A. The truth about how uber's app manages drivers. Harvard Business Review, 2016. Disponível em: https://hbr.org/2016/04/the-truth-about-how-ubers-appmanages-drivers. Acesso em: 12 jan. 2021.

SLEE, Tom. Uberização: a nova onda do trabalho precarizado. São Paulo: Elefante, 2017.

SRNICEK, N. Platform capitalism. Cambridge, UK: Polity Press. 2017.

STANDING, G. Basic Income: and how we can make it happen. Lauro de Freitas: Editora Pelicano. 2017b.

STANDING, G. O principal inimigo do precariado é o Estado. O Estado de São Paulo, especial Trabalho. 2017a. https://infograficos.estadao.com.br/focas/planeje-suavida/principal-inimigo-do-precariado-e-o-estado-diz-economista-britanico. Acesso em: 30 set. 2020.

TICONA, J; MATEESCU, A., ROSENBLAT, A. Beyond Disruption How Tech Shapes Labor Across Domestic Work \& Ridehailing. Data e Society, 2018.

VALENDUC, G.; VENDRAMIN, P. Work in the digital economy: sorting the old from the new. Working Paper, 2016.

WEST, S. M. Data capitalism: redefining the logics of surveillance and privacy.

Business e Society, 2017. DOI:10.1177/0007650317718185.2017. 
ZUBOFF, S. Big Other: surveillance capitalism and the prospects of an information civilization. Journal of Information Technology, 2016.

Recebido em: 10/10/2021

Aprovado em: 05/11/2021

Publicado em: 10/11/2021 